\title{
SVONAR: A New Quantitative Method for Studying Learner Satisfaction
}

\author{
Peter Kokol, ${ }^{1}$ Slavko Cvetek, ${ }^{1}$ Marko Kokol, ${ }^{2}$ Petra Kokol, ${ }^{2}$ and Matej Urbas ${ }^{2}$ \\ ${ }^{1}$ Faculty of Health Sciences, University of Maribor, Žitna ulica 15, 2000 Maribor, Slovenia \\ ${ }^{2}$ Faculty of Electrical Engineering and Computer Science, University of Maribor, Smetanova ulica 17, 2000 Maribor, Slovenia
}

Correspondence should be addressed to Peter Kokol, kokol@uni-mb.si

Received 8 July 2011; Revised 7 January 2012; Accepted 19 February 2012

Academic Editor: Stephen P. Heyneman

Copyright () 2012 Peter Kokol et al. This is an open access article distributed under the Creative Commons Attribution License, which permits unrestricted use, distribution, and reproduction in any medium, provided the original work is properly cited.

\begin{abstract}
We investigated students' feelings and well-being during the lesson. We were working on a problem of how to adjust teaching in the secondary school and achieve that students will feel as good as possible and better follow the instruction. A hypothesis was set that, by measuring the desired length of lesson and factors which influence lesson length, we can measure and influence student satisfaction. Based on this hypothesis we investigated the factors which have influence on lesson length in a particular subject. Data were collected by means of a questionnaire. The subjects were students of II. gimnazija (secondary grammar school). The responses were analysed to obtain correlations between the factors (average grade in a subject, boredness and likableness of the teacher, length and level of boreness of lesson content, fear of the teacher) and lesson length. Results suggest that, by modifying these factors we could change students' opinions, that is, increase their willingness to attend classes. The set hypothesis was confirmed and it was shown that by using simple diagrammatic models built on the basis of linear regression we can identify and study the influence of these factors on lesson length.
\end{abstract}

\section{Introduction}

Students in secondary schools are subject to increased demands and the syllabus has become more demanding. All participants in the educational process, both students and teachers, need to invest a lot of effort and time in order to achieve quality education and good results. This also results in a considerable time constraint and psychological pressure. Education has become difficult not only for students but also for teachers as providers of education. Solving problems like these is a considerable challenge. We decided to face the challenge knowing that our success could contribute to the effectiveness of the educational system and improved satisfaction of students and those involved in education.

Evaluation and assessment of educational systems has become a major factor in school governance. For example, Grek et al. [1] presents how the management of flows of information through quality assurance can be examined as a new form of governance, not just at the national level but within the broad policyscape of the European Union. Cohen et al. [2] defines the school climate as the quality, spheres, and character of school life which is based on patterns of people's experiences of school life and reflects norms, goals, values, interpersonal relationships, teaching and learning practices, and organizational structures, thereafter it is more than individual experience it is a group phenomenon. Students, educators, and staff work together to develop, live, and contribute to a shared school vision. Empirical research indicates that positive school climate is associated with academic achievement, school success, effective violence prevention, students' healthy development, and teacher retention. Courtney [3] argues that in a learner-centered view of education the learner's needs must be understood and the learner must be engaged within the learning process. This view is supported by EU governments in the manner that educational organizations should provide evidence that the quality of education is improving. Kyriakides and Creemers [4] introduces a 5-dimensional quality assessment model which measures frequency, focus, stage, quality, and differentiation and presents its use in the classroom showing how it can explain variation in student achievements, and Johnes [5] shows how the data envelopment analysis (DEA) can handle multiple inputs and multiple outputs and is a 
suitable technique for measuring the efficiency of education institutions.

On the other hand it has been shown that student's satisfaction and retention in educational institutions either at secondary or university level has a substantial impact on students' educational experience [6], and, consequently, the impact on the position of the institution in the education market place. Student's satisfaction with educational experience has been on one side measured with yes or no questions, or with some other simple satisfaction degree assessment [7] or, on the other side, with complex approaches like multipleitem weight gap score [7], Herzberg's two-factor theory [6], and various survey instruments $[8,9]$.

Contrary to the above approaches our aim was to develop a very simple but informative instrument which can be easily employed by the teacher or by the educational institution quality assurance teams. In the research we focused mostly on student-teacher interaction. We proposed that the desired length of instruction (lesson) in a certain subject could be used as a metrics of student satisfaction; the student will want a shorter lesson if their needs are not satisfied during instruction and, vice versa, they will want a longer lesson if their needs are satisfied. By means of a survey (questionnaire) we wanted to identify the weight of various factors that influence students' satisfaction and how this could result in changes of the length of instruction (lesson length) and consequently students' satisfaction. Based on the literature review, following two important groups of factors influencing students' satisfaction were selected "Boredom" $[10,11]$ and "Teacher characteristics" $[12,13]$ to which two additional factors "Grade" and "Subject loadedness" were added. We studied students' satisfaction in the following subjects: Slovene language, Mathematics, English language, History, Geography, and Chemistry.

1.1. Hypothesis. In our research we set the following hypothesis.

By measuring the desired length of instruction (lesson length) and factors that influence this length we can identify and influence student satisfaction.

1.2. Original Contributions. Original contributions of our research are as follows:

(i) an innovation in lesson delivery by introducing varied lesson length,

(ii) an introduction of the desired length of instruction as an indicator of student's satisfaction with a lesson,

(iii) a simple method and models for simulating the influence of various satisfaction factors on lesson length.

\section{Methods}

Our innovative theoretical proposition was that students' satisfaction with their educational experience during a single

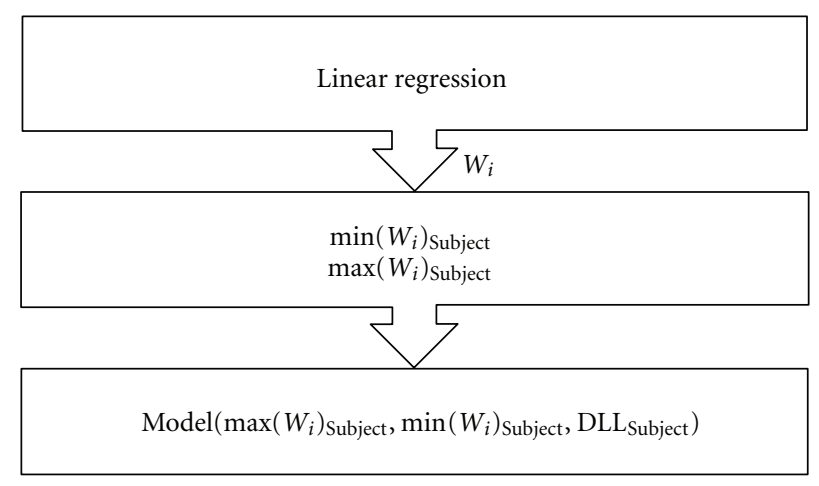

Figure 1: Building the simulation models.

lesson/instruction is directly proportional to their desired lesson length and that the lesson length is in linear relation to various factors shown in the following equation:

$$
\begin{aligned}
\mathrm{DLL}= & W_{1} \cdot \mathrm{AG}+W_{2} \cdot \mathrm{BT}+W_{3} \cdot \mathrm{BT} \\
& +W_{4} \cdot \mathrm{LT}+W_{5} \cdot \mathrm{FT}+W_{6} \cdot \mathrm{SC},
\end{aligned}
$$

where DLL is the desired lesson length, AG is the average grad, BT is the teacher boredness, LT is the teacher likeableness, FT is the fear of teacher, SC is the subject content loadedness.

2.1. Questionnaire. In the research we used a questionnaire which provided the data on the required lengths of lessons and factors influencing these lengths. The students accessed each factor except the last one using five-point Likert scale ranging from "Totally agree" to "Totally disagree".

2.2. Statistics. Statistical analysis was made by using SPSS program for Windows 16.0. The simulation models were modelled by using Microsoft@Excel 2003.

Results were analysed by using Spearman bivariate correlation test by which we determined the correlation coefficient between dependent and independent variables, and the significance of this coefficient. We then used the linear regression method by which we identified the "weight" of each independent variable and the connection between independent and variables (boredom, grade, etc.) with lesson length.

2.3. Simulation Models. For the purpose of presenting the simulation models $3 \mathrm{D}$ diagrams were made as shown in Figure 1. The diagrams were made in such a way that both independent variables are on $x$ - and $z$-axes, and lesson length is drawn on $y$-axis. In each diagram, there is one independent variable that positively influences lesson length (by increasing it increases lesson length) and one that negatively influences lesson length (by increasing it decreases lesson length). These two independent variables were selected by using linear regression method, so that we chose the variable with the strongest positive and strongest negative correlation coefficients from Table 4 . For better transparency and representation of the simulation model only two independent variables are shown in the diagram. 
TABle 1: Average (mean) lesson length as determined by students.

\begin{tabular}{lccc}
\hline Subject & Minimum lesson length & Maximum lesson length & Mean lesson length \\
\hline Slovene & 25 & 65 & 38.16 \\
Math & 25 & 65 & 30.28 \\
English & 25 & 65 & 38.67 \\
History & 25 & 65 & 38.80 \\
Geography & 25 & 65 & 37.11 \\
Chemistry & 25 & 65 & 39.68 \\
\hline
\end{tabular}

TABLE 2: Mean values of factors which influence lesson length.

\begin{tabular}{lcccccc}
\hline Subject & \multicolumn{1}{c}{ Syllabus loadedness } & Content boredness & Teacher boredness & Teacher likeableness & Fear of teacher Grade obtained in the subject \\
\hline Slovene & 2.26 & 2.61 & 2.36 & 3.00 & 2.15 & 3.30 \\
Math & 2.29 & 3.06 & 2.77 & 2.44 & 2.63 & 3.19 \\
English & 2.91 & 2.87 & 2.90 & 2.72 & 1.89 & 3.92 \\
History & 2.20 & 2.72 & 2.06 & 3.08 & 2.97 & 3.15 \\
Geography & 2.25 & 2.58 & 2.38 & 2.87 & 2.15 & 3.99 \\
Chemistry & 2.11 & 3.53 & 2.92 & 3.05 & 2.42 & 2.47 \\
\hline
\end{tabular}

\section{Results}

3.1. Sample. 79 students (39 boys and 40 girls) aged 14-17 years participated in the survey.

3.2. Descriptive Data. Table 1 shows how students of II. gimnazija Maribor assessed the appropriateness of lesson length. Most students believe that lessons are too long. It is interesting that the average values in different subjects are very similar, as well are the minimum and maximum values. The highest value of lesson length is in Chemistry and the lowest in Geography.

Table 2 shows students responses to other questions in the questionnaire. In the first column we can see how students assessed syllabus loadedness on a 1-5 scale where 1 means most loaded and 5 means least loaded syllabus. It is seen from the table that they find the syllabus most loaded in Geography and least loaded in English. On average, students think that syllabuses of all subjects are overloaded. In all other questions 5 means very much and 1 means very little. The students find the content most boring in Geography and least boring in History. They find the teacher most boring in Geography and least boring in Chemistry. They find Chemistry teacher the most likable and Math teacher the least. Students are most afraid of Chemistry teacher and least afraid of English teacher. The highest average grade (mark) was obtained in History and the lowest in Geography.

3.3. Linear Regression by Subjects. Table 3 presents data on plane coefficients that were obtained by linear regression method and are given by subjects and various teacher/syllabus/learner characteristics. Those used in the models are coloured green. As shown in the table, lesson length was between 35 and 45 minutes in most cases, with a significant exception of Geography (28 minutes) and Chemistry (60 minutes). It is also seen in the table that, in most subjects, content boredness has the biggest influence on lesson length and that this influence is negative in all cases (the bigger the boredness the shorter the lesson). Content boredness has the biggest negative influence while teacher likableness has the biggest positive influence. It is interesting that in some cases, grade negatively (!) correlates with lesson length-students with higher grades want shorter lessons.

All coefficients, however, do not have the same "weight." In Slovene language, content boredness is eight times more important than syllabus loadedness. In Math, content boredness is ten times more important than teacher likableness. In Geography, it is similar with the only difference that here we find the biggest difference between content boredness and teacher likableness. In Chemistry, grade is twenty-four times more important than teacher likableness.

3.4. Correlation Coefficients of Variables. In Table 4 we can see how strongly lesson length correlates with individual variables and how significant the correlation is. Significant correlations $(P \leq 0.05)$ are coloured blue. In most cases lesson length depends on teacher boredness (except in English)_always negatively. Similarly, the influence of content boredness is always negative. Fear of the teacher has least influence on lesson length-in our case only in History. In four of six subjects, average grade also influences lesson length. In three of these, the obtained grade positively correlates with lesson length. In one case it correlates negatively - the higher the grade the shorter is the lesson that the student wants.

3.5. Models. On the basis of obtained correlation coefficients and linear regression coefficients we could build a simulation model for identifying suitability of lesson length (duration of instruction). In all subjects, two variables were always used as independent variables: one of them with the most negative and one with the most positive influence on lesson length. In this way we could determine the factors that we would need to change in order to increase students' willingness to 
TABLE 3: Linear regression coefficient by subjects and factors.

\begin{tabular}{|c|c|c|c|c|c|c|c|}
\hline Subject & $\begin{array}{l}\text { Basic } \\
\text { length }\end{array}$ & $\begin{array}{c}\text { Syllabus } \\
\text { loadedness }\end{array}$ & $\begin{array}{c}\text { Content } \\
\text { boredness }\end{array}$ & $\begin{array}{c}\text { Teacher } \\
\text { boredness }\end{array}$ & $\begin{array}{c}\text { Teacher } \\
\text { likeableness }\end{array}$ & $\begin{array}{l}\text { Teacher } \\
\text { fear of }\end{array}$ & Grade \\
\hline Slovene & 43.33 & -0.47 & -3.57 & -0.17 & 0.77 & -0.89 & 1.62 \\
\hline Math & 43.29 & 4.57 & -3.96 & -0.41 & 0.78 & -0.04 & -1.56 \\
\hline English & 39.92 & 1.45 & -4.00 & 1.15 & 0.91 & 0.95 & -0.40 \\
\hline History & 35.92 & 0.65 & -2.25 & -1.31 & 1.02 & -0.84 & 3.06 \\
\hline Geography & 28.10 & 3.54 & -1.92 & -0.58 & 0.54 & -0.21 & 1.57 \\
\hline Chemistry & 60.68 & 3.06 & -2.97 & -1.69 & -0.17 & -0.72 & -3.96 \\
\hline
\end{tabular}

TABLE 4: Correlation coefficient and significance $(P)$ by subject and factors which influence lesson length.

\begin{tabular}{|c|c|c|c|c|c|c|}
\hline Subject & $\begin{array}{c}\text { Syllabus } \\
\text { loadedness }\end{array}$ & $\begin{array}{c}\text { Content } \\
\text { boredness }\end{array}$ & $\begin{array}{c}\text { Teacher } \\
\text { boredness }\end{array}$ & $\begin{array}{c}\text { Teacher } \\
\text { likeableness }\end{array}$ & $\begin{array}{l}\text { Teacher } \\
\text { fear of }\end{array}$ & Grade \\
\hline Slovene & 0.16 & -0.55 & -0.37 & 0.33 & -0.10 & 0.32 \\
\hline$P$ & 0.15 & 0.00 & 0.00 & 0.00 & 0.40 & 0.00 \\
\hline Math & 0.47 & -0.46 & -0.26 & 0.26 & -0.10 & 0.15 \\
\hline$P$ & 0.00 & 0.00 & 0.03 & 0.02 & 0.39 & 0.20 \\
\hline English & 0.06 & -0.44 & -0.15 & 0.12 & 0.00 & 0.02 \\
\hline$P$ & 0.59 & 0.00 & 0.19 & 0.32 & 0.97 & 0.88 \\
\hline History & 0.10 & -0.46 & -0.52 & 0.43 & -0.35 & 0.35 \\
\hline$P$ & 0.41 & 0.00 & 0.00 & 0.00 & 0.00 & 0.00 \\
\hline Geography & 0.48 & -0.40 & -0.30 & 0.15 & -0.06 & 0.34 \\
\hline$P$ & 0.00 & 0.00 & 0.01 & 0.20 & 0.63 & 0.00 \\
\hline Chemistry & 0.32 & -0.39 & -0.26 & 0.23 & -0.05 & -0.28 \\
\hline$P$ & 0.01 & 0.00 & 0.03 & 0.05 & 0.67 & 0.02 \\
\hline
\end{tabular}

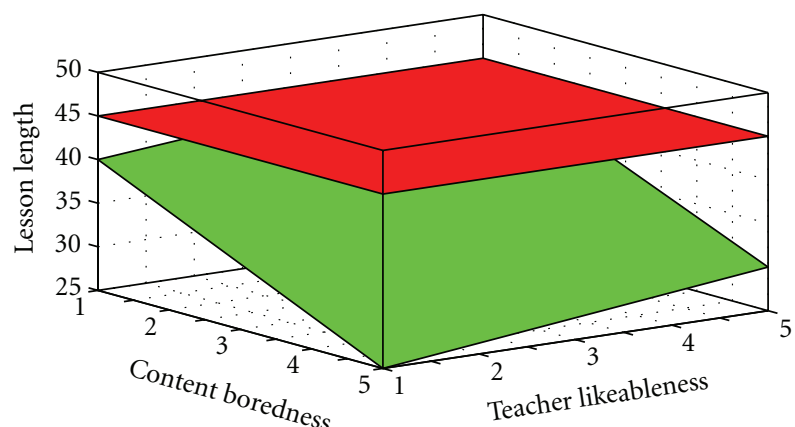

FIgURE 2: A 3-dimensional diagram showing the changing of lesson length in Slovene in correlation with content boredness and teacher likableness.

attend classes when the lesson length is 45 minutes. In Figures 2 to 8 , the plane representing 45 -minute lesson length is coloured red. The diagram in the figure made by using the above-described model is coloured green. At the intersection between these two planes the conditions suit 45-minute lesson length.

Figure 2 shows lesson length in Slovene language in correlation with content boredness and teacher likableness. It is evident that a 45-minute lesson length cannot be reached even in best possible conditions, that is, when both the teacher and the content are interesting. The shortest lesson length is 25 minutes and the longest lesson length is 43

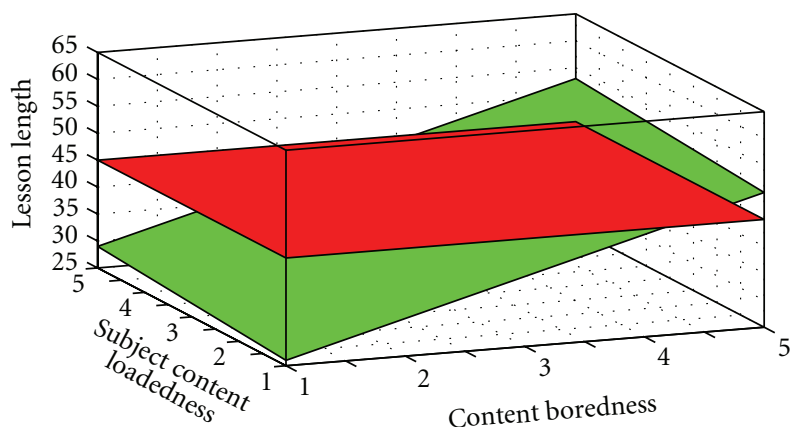

FIGURE 3: A 3-dimensional diagram showing the changing of lesson length in Math in correlation with syllabus loadedness and content boredness.

minutes. Content boredness has a bigger influence on lesson length, which is also seen in Table 3.

Figure 3 shows the changing of lesson length in Math in correlation with syllabus loadedness and lesson boredness. We can see that if the syllabus is not too loaded we do need a likeable teacher to reach 45-minute lesson length. And vice versa, if the teacher is very likeable the syllabus can be overloaded to some extent. As seen from the diagram and Table 3, both independent variables have approximately the same influence on lesson length. Minimum lesson length is 26 minutes and maximum lesson length is 65 minutes. 


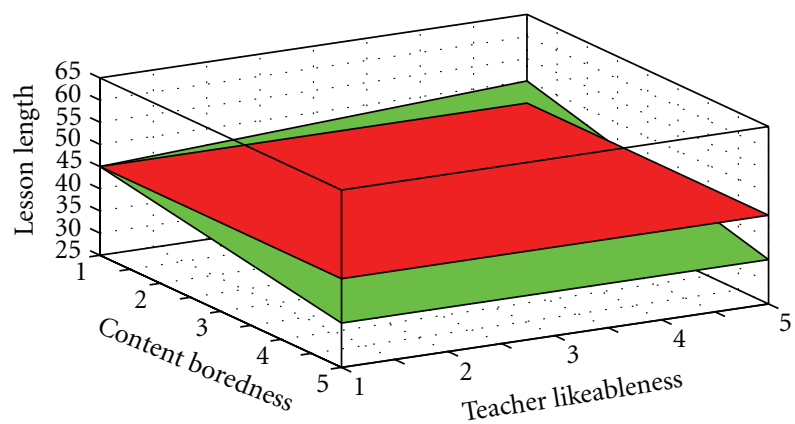

FIGURE 4: A 3-dimensional diagram showing the changing of lesson length in English in correlation with content boredness and teacher likeableness.

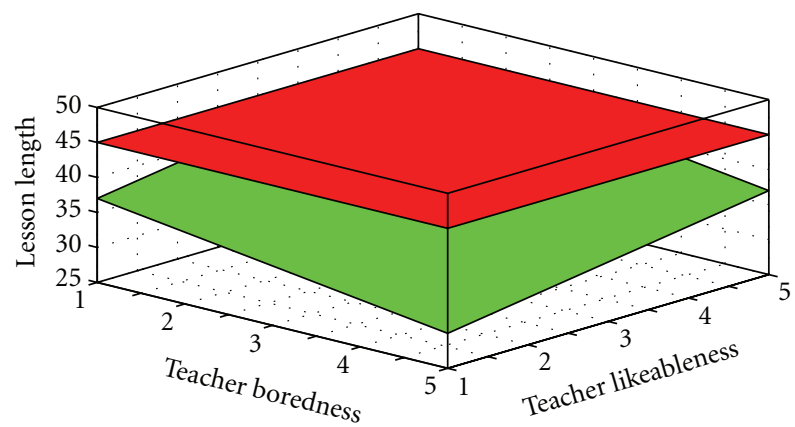

FIgURE 5: A 3-dimensional diagram showing the changing of lesson length in History in correlation with teacher boredness and teacher likeableness.

Figure 4 shows the changing of lesson length in English in correlation with content boredness and teacher likableness. We can see that lesson length of about 45 minutes can be obtained if the content is interesting even if the teacher is unlikeable. In case where we have both an interesting content and a likable teacher the lesson can be 55 minutes long. In an English lesson, content boredness has most influence on lesson length (Table 1). Minimum lesson length is 25 minutes and maximum lesson length is 55 minutes.

Figure 5 shows the changing of lesson length in History in correlation with teacher boredness and teacher likableness. We can clearly see that even in best conditions (when the teacher is both likeable and interesting) we cannot obtain 45-minute lesson length. In History, both variables have approximately the same influence while teacher boredness has a slightly bigger influence. Minimum lesson length is 25 minutes and maximum lesson length is 40 minutes.

Figure 6 shows the changing of lesson length in Geography in correlation with syllabus loadedness and content boredness. We can see that to obtain a 45-minute lesson we must have either a normally loaded syllabus or the content must be interesting to students to at least medium (average) degree. Syllabus loadedness has bigger influence here, as shown in Table 1. Minimum lesson length is 35 minutes and maximum lesson length is 55 minutes.

Figure 7 shows the changing of lesson length in Chemistry in correlation with syllabus loadedness and content

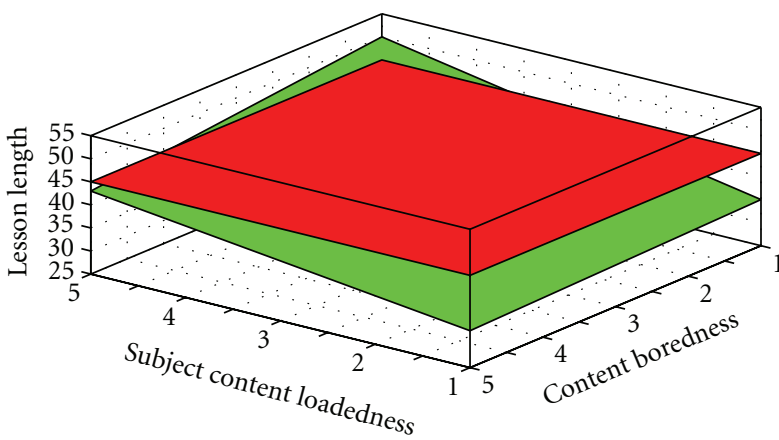

FIGURE 6: A 3-dimensional diagram showing the changing of lesson length in Geography in correlation with syllabus loadedness and content boredness.

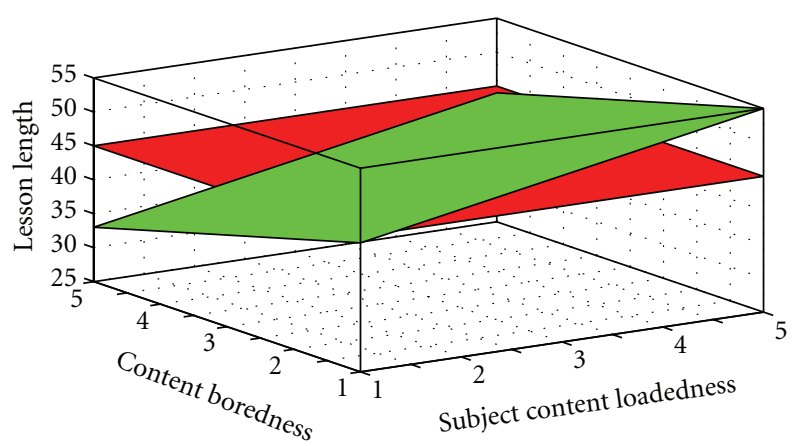

Figure 7: A 3-dimensional diagram showing the changing of lesson length in Chemistry in correlation with syllabus loadedness and content boredness.

boredness. We can see that if the content is very interesting the syllabus can be overloaded and we will nevertheless get a 45-minute long lesson. And vice versa, if the content is very boring we need a less loaded syllabus to get a 45-minute lesson. Both independent variables (syllabus loadedness and content boredness) have approximately the same influence on lesson length. Minimum lesson length is 35 minutes and maximum lesson length is 55 minutes.

Figure 8 shows the changing of lesson length in Chemistry in correlation with content boredness and grade. It is seen from the diagram that students with lover grades wish to have longer lessons. However, if we wish to have a 45minute lesson also with better students, the content of the lesson must be interesting.

\section{Discussion}

4.1. Descriptive Statistics. Students want the longest lessons in Chemistry, which is probably because the syllabus is not overloaded, the teacher is likable and the students have a high average grade. Students want the shortest lessons in Geography, which probably results from the overloaded syllabus, low average grade, and content and teacher boredness. It is interesting that lesson length was not increased even with relatively high teacher likableness (the second most likable). 


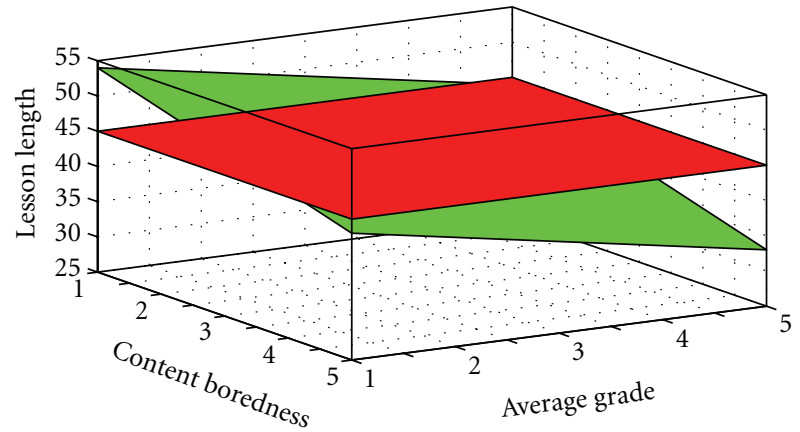

FIGURE 8: A 3-dimensional diagram showing the changing of lesson length in Chemistry in correlation with content boredness and grade.

4.2. Linear Regression Coefficients. Linear regression analysis has shown that, in some subjects, certain factors have much higher influence than others. The biggest difference is, for example, in Chemistry where the difference between content boredness and teacher likableness is $29 \mathrm{x}$.

4.3. Slovene Language. Here, the biggest difference is between content boredness and teacher likableness where content boredness is more important. This can be most easily explained by the fact that even if the syllabus is much loaded, the student can still learn the content provided that it is interesting. If it is boring, however, he/she will probably not have interest for learning although there might not be much content to learn.

4.4. Mathematics. In Math, the biggest difference is between content boredness and teacher (the biggest difference is, in fact, between content boredness and fear of teacher but fear of teacher is such an unimportant factor that it could be included in our analysis) where content boredness is more important. This is probably because Math is a science where the teacher does not have such a big influence on lesson boredness - it all depends on what he/she is supposed to teach.

4.5. Geography. In Geography, the result it similar as in Math with the only exception that here we have teacher likableness instead of teacher boredness. That likableness is less important than boredness can be explained by the fact that, students show some interest in learning only those things that they find interesting while the rest they find unimportant.

4.6. Chemistry. In Chemistry, the biggest difference is again between content boredness and teacher likableness. This can be explained also by the fact that in Chemistry, students have laboratory classes which, besides being practical, make Chemistry interesting. For this reason boredness (in fact, interestingness) becomes more important because like likableness it also does not have a low regression coefficient.

4.7. Correlation Coefficients of Variables. It is interesting that, in all subjects, content boredness significantly correlates with lesson length while fear of teacher has significant influence only in history.

4.7.1. Slovene Language. In Slovene language, lesson length is influenced by all factors except by fear of teacher and syllabus loadedness. The fact that syllabus loadedness does not have a significant influence on lesson length can most probably be explained by the ability of the teacher to divide the syllabus according to his/her wishes and change the order of lesson units. In this way, students do not find the syllabus too or not enough loaded.

4.7.2. Math. In Math, the same factors have influence as in Slovene language, only that in math, syllabus loadedness also has some influence. In math, as different from Slovene language, the content must be taught in an orderly manner because the new content is strongly connected with the previous one.

4.7.3. English Language. In English language it is interesting that only content boredness has significant influence on lesson length. This is probably because students are aware of the importance of this world language and also meet the language in very dynamic and interesting environments (internet chat rooms, TV, etc.). So, they find the traditional way of presenting content boring while other factors are less important and do not have influence.

4.7.4. History. In History, all factors except syllabus have influence on lesson length. Students probably find the syllabus unimportant since they are aware that, in History, syllabus is more or less unchangeable. Since they find the content mostly interesting they want to influence the lesson length through other factors, they want entertaining classes, interesting teacher, good grades, and so forth.

4.7.5. Geography. All factors except fear of teacher and teacher likableness have influence on Geography. This can be probably explained by the fact that students want to achieve good grades and at the same time they want to have lessons more entertaining. Besides, they probably feel that lessons can be more entertaining if the syllabus is adjusted and is not overloaded.

4.7.6. Chemistry. In Chemistry, all factors except fear of teacher have influence on lesson length. Here, it is very interesting that grade negatively correlates with lesson length. This means that better students want shorter lessons. This can be most easily explained by the fact that better students understand the content (subject matter) more quickly while weaker students need more time and instruction. This also explains the wish for an entertaining and likable teacher, since better students probably want more entertaining lessons while weaker students, besides this, prefer a teacher who would provide encouragement and support. 
4.8. Diagrams. Results vary according to subjects. In some subjects, it is possible to exceed the set lesson length (45 minutes), namely, in Math, English, Geography, and Chemistry. In one case we could see that by changing factors we cannot achieve the set lesson length. In diagrams, the desired lesson length is presented in correlation with two factors which are most influential.

4.8.1. Math. In "Math" diagram we can see how syllabus loadedness and teacher likableness influence lesson length. Syllabus has a positive influence on students. The less content there is in the syllabus the more interest will students be in attending classes. It is similar with teacher likableness. The more likable he/she is the more time students will want to spend in class.

In Math, content requires a lot of abstract thinking. The bigger the content (syllabus) the more difficult it is for the student to follow the instruction. If the student is unable to progress according to the syllabus, he/she will soon lag behind and be subject to time and mental pressure. The student will not feel good in this subject and will not progress.

The teacher explains the content. How effective his/her explanation will be for a particular student much depends on the student's involvement. Math is a subject in which good explanation is very important. If the student finds the teacher likable he/she will invest more effort to understand the content that is being explained. For this reason the teacher should be willing to help and stimulate the student.

The student will feel better during a math class if the syllabus is shorter and the teacher is likable.

4.8.2. English Language. In "English" diagram, lesson length is presented in correlation with content boredness and teacher likableness. Teacher likableness has a positive influence on lesson length. Lesson boredness has a negative influence on lesson length.

A boring lesson in English has much influence on lesson length. As the analysis showed, by changing only this factor we cannot obtain a 45-minute lesson. It is important for students that English lessons are fun (entertaining).

Teacher likableness does not influence lesson length as much as content boredness does. However, it is only by changing this factor that we can reach or exceed a 45-minute lesson in this subject.

Thus, it is important for students that the content is entertaining. In order to motivate the students we should make English language teaching more varied.

The students will spend most time in an English class if the teacher is more likable and the content is less boring.

4.8.3. Geography. The "Geography" diagram has two independent variables: "syllabus" which has a positive influence on lesson length and "content boredness" which has a negative influence on lesson length.

The students connect lesson boredness and syllabus loadedness with the length of a geography lesson. The student will want to spend most time in class if the content is less boring and the syllabus less loaded.

In Geography, it is important for students to be able to follow the instruction and learn interesting facts.

If the syllabus is too loaded the student will be dissatisfied because it will be more difficult for him/her to follow the instruction. By making lessons more varied, however, it is possible even in this case to get lesson length of 45 minutes.

The best result can be achieved when the content is the least boring and the syllabus the least loaded.

4.8.4. History. In the "History" diagram, lesson length is given in correlation with teacher boredness and teacher likableness. Students' answers suggest that maximum expected lesson length does not even reach 45 minutes. Students are aware (more than with any other subject) that history is already written and cannot be changed. It is important for the students that the teacher provides pleasant atmosphere during the lesson. The teacher must not be boring and he/she must try to make the lesson interesting.

In history, it is important that the student becomes attracted by the topic which can be achieved by using the appropriate approach.

In this way we can achieve and optimum lesson length when the teacher is most likable and interesting.

4.8.5. Chemistry. In Chemistry, syllabus and content boredness are independent variables while lesson length is a dependant variable.

Students can better follow the instruction if the syllabus is not too loaded. Students think that the atmosphere in a chemistry lesson depends, above all, on content boredness which means that it is the teacher's main task in Chemistry that the content is presented in an interesting way.

In secondary schools, Chemistry lessons include laboratory work. A subject which includes laboratory work is more interesting which might have influence on students and could explain the relatively high maximum lesson time and relatively low oscillation $(45 \pm 10)$.

\section{Conclusion}

In our research we investigated students' feelings and wellbeing during the lesson. We were dealing with a problem of how to adjust teaching in the secondary school and make the students feel good as much as possible and thus better follow the instruction. A hypothesis was set that, by measuring the desired lesson length and factors which influence lesson length, we can measure and influence student satisfaction. Based on this hypothesis we investigated the factors which have influence on lesson length in a particular subject.

It was found that the same factors are in different relationships towards the desired lesson time in different subjects. In some subjects, lesson time is related with almost all factors and in English only with one.

Our research was successful. It has shown that by simple identification of the desired length of instruction (lesson length) and factors which influence this length we can learn 
a lot about the quality of teaching and show, by setting simple simulation models, how it could be improved. In our research, however, some more questions were raised.

(i) What would be the results in other schools, such as vocational or elementary schools?

(ii) How to investigate and show the influence of more factors simultaneously?

(iii) How are these problems seen by teachers and school administration?

(iv) How would the models look like if both students' and teachers' opinions are taken in consideration.

\section{References}

[1] S. Grek, M. Lawn, B. Lingard, and J. Varjo, "North by northwest: quality assurance and evaluation processes in European education," Journal of Education Policy, vol. 24, no. 2, pp. 121-133, 2009.

[2] J. Cohen, E. M. Mccabe, N. M. Michelli, and T. Pickeral, "School climate: research, policy, practice, and teacher education," Teachers College Record, vol. 111, no. 1, pp. 180-213, 2009.

[3] J. Courtney, "Do monitoring and evaluation tools, designed to measure the improvement in the quality of primary education, constrain or enhance educational development?" International Journal of Educational Development, vol. 28, no. 5, pp. 546559, 2008.

[4] L. Kyriakides and B. P. M. Creemers, "Using a multidimensional approach to measure the impact of classroomlevel factors upon student achievement: a study testing the validity of the dynamic model," School Effectiveness and School Improvement, vol. 19, no. 2, pp. 183-205, 2008.

[5] J. Johnes, "Data envelopment analysis and its application to the measurement of efficiency in higher education," Economics of Education Review, vol. 25, no. 3, pp. 273-288, 2006.

[6] O. W. DeShields, A. Kara, and E. Kaynak, "Determinants of business student satisfaction and retention in higher education: applying Herzberg's two-factor theory," International Journal of Educational Management, vol. 19, no. 2, pp. 128 $139,2005$.

[7] K. M. Elliott and D. Shin, "Student Satisfaction: an alternative approach to assessing this important concept," Journal of Higher Education Policy and Management, vol. 24, no. 2, pp. 197-209, 2002.

[8] L. Zhai, "Validation of an instrument to measure community college student satisfaction," Community College Journal of Research and Practice, vol. 36, no. 1, pp. 47-58, 2012.

[9] S. L. Appleton-Knapp and K. A. Krentler, "Measuring student expectations and their effects on satisfaction: the importance of managing student expectations," Journal of Marketing Education, vol. 28, no. 3, pp. 254-264, 2006.

[10] T. Belton and E. Priyadharshini, "Boredom and schooling: a cross-disciplinary exploration," Cambridge Journal of Education, vol. 37, no. 4, pp. 579-595, 2007.

[11] S. Mann and A. Robinson, "Boredom in the lecture theatre: an investigation into the contributors, moderators and outcomes of boredom amongst university students," British Educational Research Journal, vol. 35, no. 2, pp. 243-258, 2009.

[12] P. Goldschmidt and G. Phelps, "Does teacher professional development affect content and pedagogical knowledge: how much and for how long?" Economics of Education Review, vol. 29, no. 3, pp. 432-439, 2010.

[13] S. Kukla-Acevedo, "Do teacher characteristics matter? New results on the effects of teacher preparation on student achievement," Economics of Education Review, vol. 28, no. 1, pp. 49-57, 2009. 


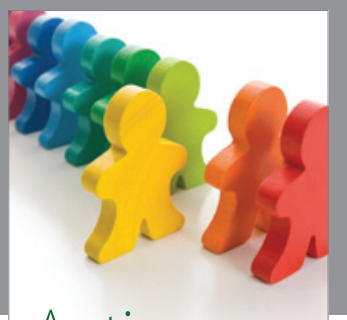

Autism

Research and Treatment
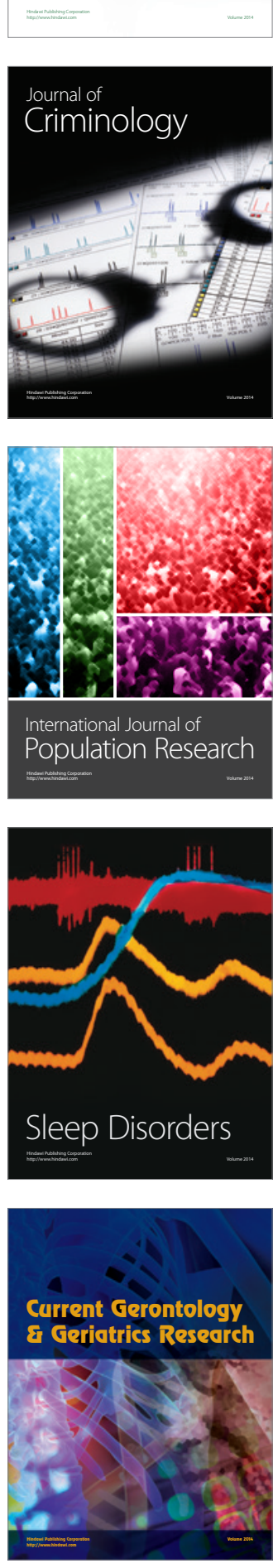
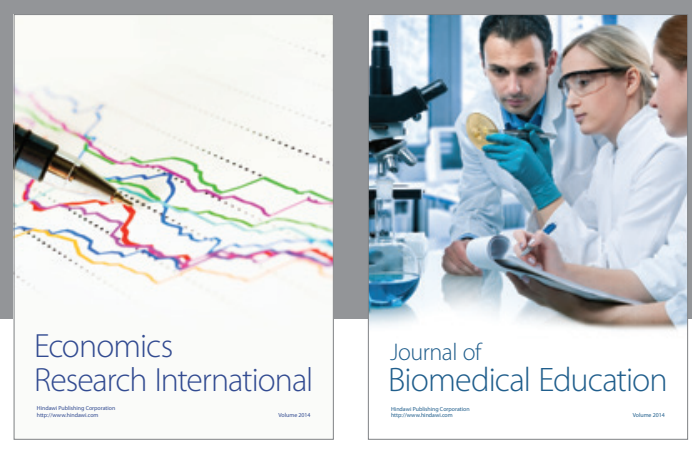

Journal of

Biomedical Education

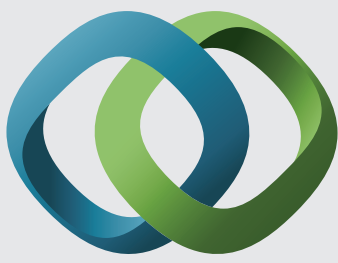

\section{Hindawi}

Submit your manuscripts at

http://www.hindawi.com
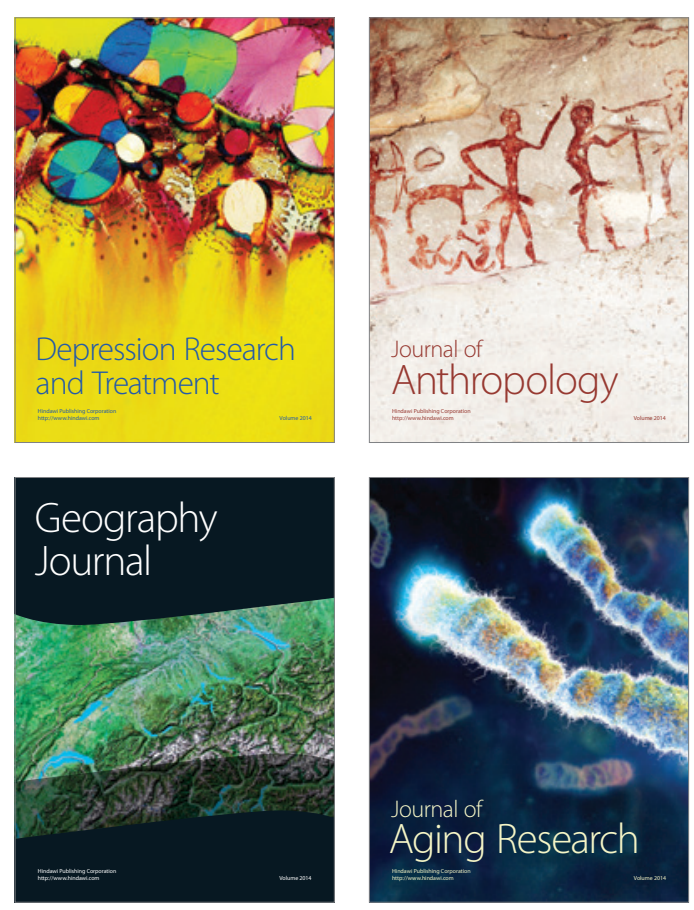

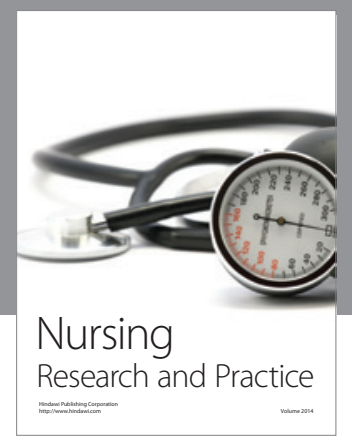

Nursing

Research and Practice

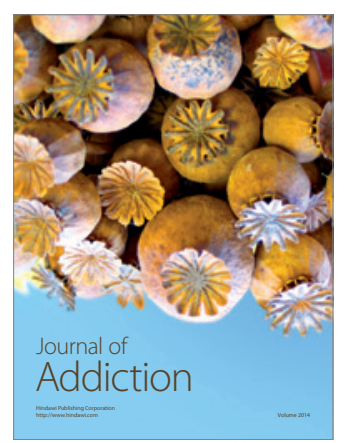

Child Development

Research

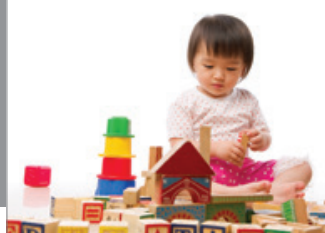

迥
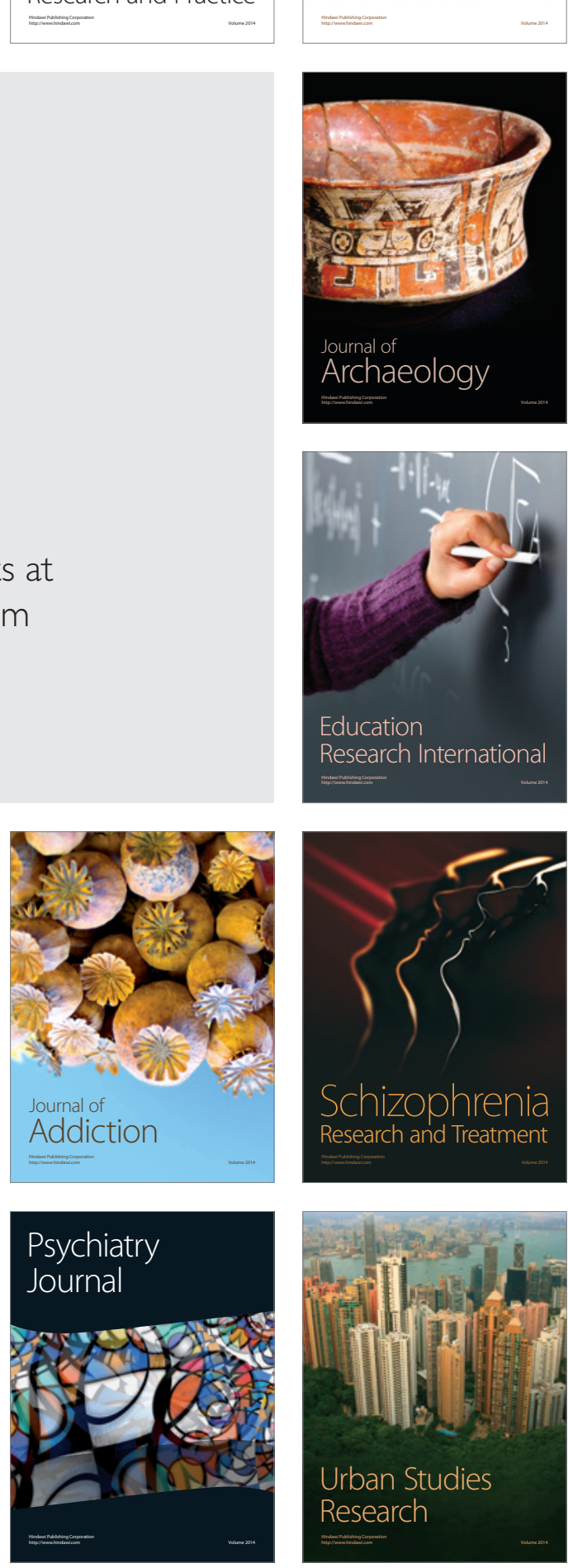